\title{
Sign Language Information Detection through Mobile or Telephonic Communication
}

\author{
Syed Asif Ali \\ Department of Computer Sciences \\ SMI University Karachi Pakistan
}

\begin{abstract}
Special persons are the part of every culture all over the words. There are different types of special persons (like blind, deaf, physically disabled and mentally distorted persons). This research work only contribution for special persons who are deaf. Communication is a way by which persons can interact with other person of community in their social circle. Deaf persons as a part of any community faced lot of problems to interact with normal persons in society because they have not hearing or speaking and sometimes both i.e. as deafness.
\end{abstract}

Due to the communication barrier deaf person are not able to participate any activity of society along with normal persons. During the last few years, the advantage of information and communication technologies has been progressively and impressively applied for overcome the communication barrier between deaf and normal persons. The technologies and their applications have been varied, for example computer assisted instructions, communication and sensory methods of communications etc.

The main purpose of this research work is to mitigate the communication gap between deaf and normal persons by use of Information and Communication Technology (ICT).

Using the proposed framework deaf persons can easily assimilate in specific workplace and can mixed with culture of normal people.

KEYWORDs: Sign Language pattern, Patten matching.

\section{INTRODUCTION}

The graph of Deaf persons is increasing day by day all over the world [1]. During the last decade the use of information and communication technology is also increasing [2].

Thus it is the right time to avail IT facilities to create a framework to impart Information and Communication Technology for Deaf persons in a similar environment which is available for a normal person. Using ICT deaf persons can play vital and productive role in society at all levels of communication. In this paper an effort is being made to overcome the communication gap between normal and deaf persons.

\subsection{COMMUNICATION}

Communication is a way by which one can exchange views or opinions from one person to another person. These views can transmit in the form of voice, text or signs. Information and communication minimized the communication gap between two or more people, which help them to enhance their social network. Communication is to help people feel good quality relation to themselves and about their friends, groups, and organizations. For true communication, there should be a transmission of thoughts, ideas and feelings beginning one mind to another [3].

\subsection{COMMUNICATION FOR DEAF \\ CULTURE}

The Deaf are a distinct cultural-linguistic people group. This will be the biggest conceptual barrier you face as you seek to understand the Deaf community and effective outreach within it. If you can step out of your hearing view of the world for a moment and see Deaf people as a cultural-linguistic group, then all that we do will begin to make sense. If you can't, and you continue to see deafness as simply a physical disability, then you probably won't understand or agree with much of what we say or do.

Historically and internationally, Deaf people live and interact as a distinct people group. They have their own customs, habits, thought patterns, language, common experiences, and values that identify them as a unique cultural group. They do not consider themselves handicapped or disabled; rather, they consider themselves a minority group within the context of their own home country [4].

\section{SIGN LANGUAGE LITERACY}

Signed languages are as old as history. They are not new languages recently invented. Like spoken languages, they developed naturally. Deaf people needed to communicate with those around them. Certain gestures became commonly understood and in time, as with spoken languages, a rich vocabulary and grammar structure developed. Like spoken languages, signed languages are living languages. They change as the people who use them change. Figure 1 show symbols of Sign language.

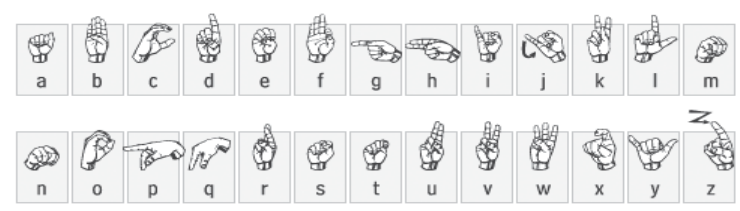

Figure 1: Sing Language for Deaf Persons

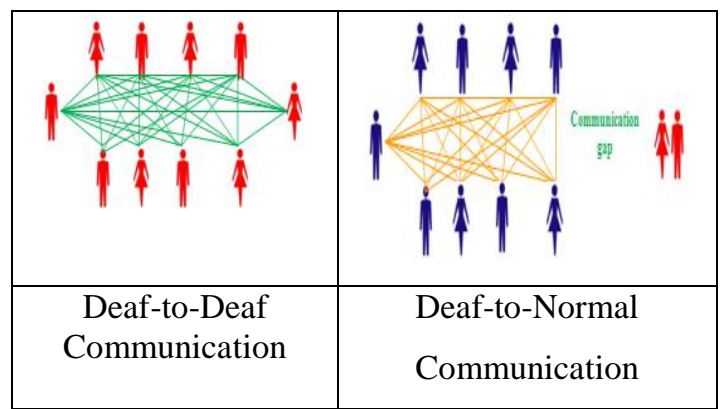


In spoken language, the different types of sounds created by words and tones of voice are the most important devices used to communicate. Sign language is based on the idea that sight is the most useful tool a deaf person has to communicate and receive information. Thus, American Sign Language (ASL) uses hand shape, position, and movement; body movements; gestures; facial expressions; and other visual cues to form its words.

American Sign Language is used in America; it is a language completely separate from English. It contains all the fundamental features a language needs to function on its own--it has its own rules for grammar, punctuation, and sentence order [5], [6].

American Sign Language evolves as its users do, and it also allows for regional usage and jargons. Every language expresses its features differently; American Sign Language is no exception. English speakers often signal a question by using a particular tone of voice; American Sign Language users do so by raising the eyebrows and widening the eyes.

There is not just one international signed language in the world. There is a different signed language in every country. Some countries have several signed languages.

\section{COMMUNICATION MODEL FOR DEAF}

Today communication between deaf and nonhandicapped people is only possible:

- If the non-handicapped person can handle the sign language,

- If the deaf person communicates loud and clear (if possible),

- If both write sms via mobile phone.

At the moment there is no electronic device or service that enables communication between both in the way, that the deaf person uses sign language and the non-handicapped person talks.

In Social interaction deaf persons need to communicate with their own culture (i.e. Deaf-to-Deaf Communication) and also interact with normal persons in daily life.

Therefore two types of communication model is exit for deaf persons:

1-Deaf-to-Deaf (DTD) Communication Model

\section{2-Deaf-to-Normal (DTN) Communication Mode}

The DTDCommunication Model is comfortable for deaf persons. In this model they communicate in their own cultured language i.e. sign language.

The DTNCommunication Modelis difficult for deaf persons to interaction with normal persons in daily routine. They faced lot of problem to communicate with normal persons. Because normal persons are not aware with sign language. Normal person with hearing blessed also feel frustration to communicate with deaf persons, especially when there is no interpreter between them. They have communication barrier with deaf persons. Deaf person also have their own culture and feel comfortable to communicate with other deaf person.

The unemployment rate between deaf people is twice that of people without deafness

(Normal).Attempts to assimilate deaf persons into the workplace is not just a social compulsion, if deaf persons assimilate in job, they can improve their living standard and their families will grow, and the level of poverty will reduce.

The first step for getting job is interview. Deaf persons face problem from the beginning of the employment step. How he /she can understand interview question in DTN model? And how deaf can response the questions of interview? .Proposed model reduce the communication barrier in DTN environment. Therefore deaf persons can easily delivered their messages and understand the talk of normal persons. So that deaf persons can successfully assimilate in work places too.

This is an era of information and communication technology and with the information technology can easily develop a system which reduces the communication gaps or barrier between deaf and normal persons. The deaf persons can acquire immense benefit with information and communication technology like email service voice chatting, Video Conference, Mobile/telephone Communication etc.

In proposed model mobile or telephonic communication is used to reduce communication barrier between deaf and normal persons. Mobile or telephone is a device that enables communication between deaf and normal persons by using few additional features.

\section{Sign Language Information Detection through Mobile or telephonic communication}

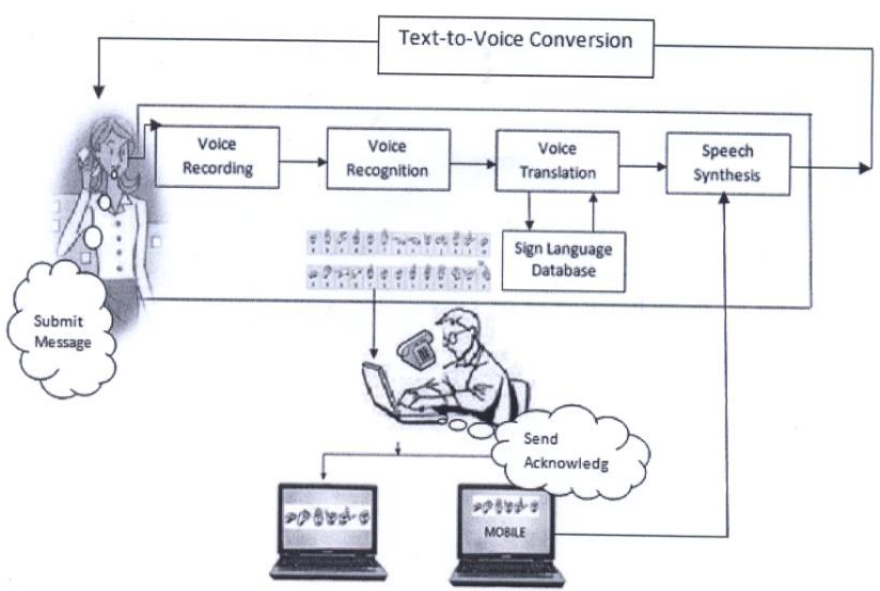

Step1-The deaf person receives call via mobile/telephone.

Step 2- On picking mobile/telephone call it will record in first step on computer system or on communication device.

Step 3- In next step computer will recognize the voice and translate into text format. 
Step 4- The text will translate into sign language from database of sign language saves on system [7],[8].

Step 5- When operator type answer from system then it again converts into speech and send to the caller.

Most of the deaf persons are deaf and dumb, as they

have hearing ability so they can't listen any things that why they are not able to speak too .

\section{Features of Proposed Model}

-Provide more Job opportunities to deaf persons, so deaf persons can easily assimilate in work place.

-For Normal persons there are no needs to learn deaf cultural language (Sign Language).

-The voice message receive through mobile or telephone and convert into sign language, so this is very comfort for deaf people to serve with working environment of normal persons without DTN barrier.

-Documentation is a illegal part of any organization, this system facilitated to maintain documentation in both sign and normal language.

\section{Conclusion}

Recent technologies show an important part in development of the entire society. Disabled persons are also apart every society. Assistive technology is important play very important rolebecause, without assistive technology they will have no access or be able to benefit from their educational program and other matter of their life. Suggest system will be helpful for deaf persons to assimilate then in different work places. This is lan interactive communication system for them.

\section{References}

[1] John C Martin, "Introduction to languages and Automata Theory", Fourth Edition, Published by McGraw-Hill, 2003.

[2] A. Thomas Sudkamp, 'Automata Theory, Languages, and Computation', Third Edition, Addison-Wesley, 2005.

[3] Don Cabbage Ph.D. ,'ASL II American Sign Language Thesaurus' International Communication Publishers PO Box 371007, E1 Paso, TX79937 (915)855-7575

[4] Martin L.A. Sternberg, 'American Sign Language Dictionary', Third Edition'.

[5] Minjun Wang, Geoffrey Fox, Marlon Pierce, 'Collaboration Entities on Deterministic Finite Automata, Las Vegas', NV, USA, May 14-May 17, ISBN: 0-9785699-0-3.

[6] Lucas, S.M.; Reynolds, T.J.; , "Learning deterministic finite automata with a smart state labeling evolutionary algorithm," , Pattern Analysis and Machine Intelligence, IEEE Transactions on,vol.27,no.7,pp.10631074,July2005,doi:10.1109/TPAMI.2005.143URL: http ://ieeexplore.ieee.org/stamp/stamp.jsp?tp=\&arnumber= $1432740 \&$ isnumber $=30890$

[7] Ong, S.C.W.; Ranganath, S.; , "Automatic sign language analysis: a survey and the future beyond lexical meaning," Pattern Analysis and Machine Intelligence, IEEE Transactions on, vol.27, no.6, pp. 873- 891, Jun 2005 doi: 10.1109/TPAMI.2005.112 URL: http://ieeexplore.ieee.org/stamp/stamp.jsp?tp=\&a rnumber $=1432718 \&$ isnumber $=30761$

[8] Automatic Sign Language Analysis: A Survey and the Future beyond Lexical Meaning,June 2005 (vol. 27 no. 6),pp. 873-891,Sylvie C.W. Ong,SurendraRanganath 